\title{
Identifikasi kesesuaian lahan tanaman pangan di Kecamatan Ngaha Ori Anggu, Kabupaten Sumba Timur
}

\author{
Identification of land suitability for food plants in Ngaha Ori Anggu Sub-District, East Sumba Regency \\ Yonce Melyanus Killa ${ }^{1}$ \\ ${ }^{1}$ Program Studi Agroteknologi Universitas Kristen Wira Wacana Sumba, Indonesia \\ *Email korespondensi: yonce@unkriswina.ac.id
}

Diterima: 11 Januari 2021 / Disetujui: 09 September 2021

\begin{abstract}
Ngaha Ori Anggu sub-district of East Sumba Regency of East Nusa Tenggara Province (NTT) has the potential of available natural resources and has not been managed optimally. One of them is the potential of land that has various characteristics. This research was conducted to find out the characteristics of the land and the suitability of food crops in Ngaha Ori Anggu Sub-District of East Sumba Regency. The analysis used in this study is the analysis of land characteristics and the analysis of land suitability. Land suitability analysis using two methods, namely overlaying observation parameters using geographic information system (GIS) through extension model builder on Arcview software and method of matching land characteristic parameters with criteria for land suitability according to Djaenudin et al. (2003). The results of the land suitability analysis show the class of suitability of rice plants in Ngaha Ori Anggu sub-district, namely S1 (highly Suitable) 10,575 ha (24.47 \%), S2 (moderately suitable) 32,614 ha (75.53\%). Corn cropland suitability class is S1 (highly Suitable) 890.7 ha (2.06 $\%$ ) and S2 (moderately suitable) 42,327 ha (97.92\%). Peanut land suitability class is S2 (Appropriate Enough) 43,216 ha (100 $\%$ ). The land suitability class of cassava plants is S1 (highly Suitable) 539.48 ha (1.24 \%), S2 (moderately suitable) $39,214.70$ ha (90.74\%), and S3 (Marginal suitable) 3,462, 80 ha (8.01\%). The matching result is obtained by the main limiting factors namely oxygen availability (ao) such as drainage, erosion hazard (eh) or slopes, water availability (wa) or rainfall, temperature (tc) or average temperature $\left({ }^{\circ} \mathrm{C}\right)$.
\end{abstract}

Keywords: land characteristics, land suitability, food crops.

\section{ABSTRAK}

Kecamatan Ngaha Ori Anggu Kabupaten Sumba Timur Provinsi Nusa Tenggara Timur (NTT) memiliki potensi sumber daya alam yang tersedia dan belum dikelola secara optimal. Salah satunya yaitu potensi lahan yang beragam karakteristiknya. Penelitian ini dilakukan untuk mengetahui karakteristik lahan dan kesesuaian lahan tanaman pangan di Kecamatan Ngaha Ori Anggu Kabupaten Sumba Timur. Analisis yang digunakan dalam penelitian ini adalah analisis karakteristik lahan dan analisis kesesuaian lahan. Analisis kesesuaian lahan menggunakan dua metode yaitu overlay parameter pengamatan dengan menggunakan sistem informasi geografis (GIS) melalui extension model builder pada software Arcview dan metode pencocokan parameter karakteristik lahan dengan kriteria kesesuaian lahan tanaman menurut Djaenudin et al. (2003). Hasil analisis kesesuaian lahan menunjukkan kelas kesesuaian lahan tanaman padi di Kecamatan Ngaha Ori Anggu yaitu: S1 (Sangat Sesuai) 10.575 ha (24,47 \%), S2 (Cukup Sesuai) 32.614 ha (75,53 \%). Kelas kesesuaian lahan tanaman jagung yaitu: S1 (Sangat Sesuai) 890,7 ha (2,06 \%) dan S2 (Cukup Sesuai) 42.327 ha (97,92 \%). Kelas kesesuaian lahan tanaman kacang tanah yaitu: S2 (Cukup Sesuai) 43.216 ha (100\%). Kelas kesesuaian lahan tanaman ubi kayu yaitu: S1 (Sangat Sesuai) 539,48 ha (1,24 \%), S2 (Cukup Sesuai) 39.214,70 ha (90,74 \%), dan S3 (Sesuai Marginal) 3.462, 80 ha (8,01\%). Hasil pencocokan diperoleh faktor pembatas utama yaitu ketersediaan oksigen (ao) seperti drainase, bahaya erosi (eh) atau lereng, ketersediaan air (wa) atau curah hujan, temperatur (tc) atau temperatur rerata $\left({ }^{\circ} \mathrm{C}\right)$.

Kata kunci: karakteristik lahan, kesesuaian lahan, tanaman pangan.

\section{PENDAHULUAN}

Kecamatan Ngaha Ori Anggu Kabupaten Sumba Timur Provinsi Nusa Tenggara Timur (NTT) memiliki potensi sumber daya alam yang tersedia dan belum dikelola secara optimal. Salah satunya yaitu potensi lahan yang beragam karakteristiknya. Hardjowigeno dan Widiatmaka (2007) menjelaskan bahwa lahan mencakup pengertian lingkungan secara fisik termasuk iklim, topografi/relief, tanah, hidrologi, dan bahkan keadaan vegetasi alami yang semuanya secara potensial akan berpengaruh terhadap penggunaan lahan.

Lahan diartikan sebagai lingkungan fisik yang terdiri atas iklim, relief, tanah air, flora, dan fauna serta bentukan hasil budaya manusia (Arsyad, 2007). Lahan adalah suatu lingkungan fisik yang meliputi tanah, iklim, relief, hidrologi, 
dan vegetasi, dimana faktor-faktor tersebut mempengaruhi potensi penggunaannya. Termasuk didalamnya adalah akibatakibat kegiatan masa lalu maupun sekarang, seperti reklamasi daerah-daerah pantai, penebangan hutan, dan akibat-akibat yang merugikan seperti erosi dan akumulasi garam (Hardjowigeno dan Widiatmaka, 2007). Lahan dalam pengertian yang lebih luas termasuk bagian yang telah dipengaruhi oleh berbagai aktivitas flora, fauna, dan manusia baik di masa lalu maupun masa sekarang. Sebagai contoh aktivitas dalam penggunaan lahan pertanian, reklamasi lahan dan rawa pasang surut atau tindakan konservasi tanah pada suatu lahan tertentu (Djaenudin et al., 2003).

Pemanfaatan lahan sebagai sumberdaya alam, khususnya dalam pengembangan suatu komoditas pertanian perlu mempertimbangkan aspek-aspek kelestarian lingkungan dan harus sesuai dengan tingkat kesesuaian dan potensi lahan (Hardjowigeno dan Widiatmaka, 2007). Tingkat kesesuaian suatu lahan perlu dilihat dengan melakukan evaluasi terhadap lahan yang dimaksud. Evaluasi lahan merupakan proses penilaian potensi suatu lahan untuk penggunaan-penggunaan tertentu (Hardjowigeno dan Widiamaka, 2007). Evaluasi lahan secara fisik dapat menjawab tingkat kesesuaian lahannya dan secara ekonomik akan menjawab kelayakan usaha taninya. Secara spesifik, kesesuaian lahan untuk suatu komoditas dinilai berdasarkan sifat fisik lingkungan seperti tingkat kesuburan tanah, iklim, topografi (kelas kelerengan), hidrologi, dan drainase (Balai Penelitian Tanah, 2003).

Kesesuaian lahan adalah kecocokan suatu lahan untuk penggunaan tertentu, sebagai contoh penggunaan lahan untuk irigasi, tambak, pertanian tanaman semusim atau pertanian tanaman tahunan (Arsyad, 2007; Azis et al., 2005). Inti dari evaluasi kesesuaian lahan adalah membandingkan persyaratan yang diminta oleh tipe penggunaan lahan yang akan diterapkan dengan sifat-sifat lahan yang dimiliki lahan yang akan digunakan. Persyaratan tumbuh tanaman meliputi: energi radiasi, temperatur, kelembaban, oksigen, dan unsur hara. Persyaratan temperatur dan kelembaban umumnya digabungkan, dan selanjutnya disebut sebagai periode pertumbuhan. Persyaratan lain berupa media perakaran, ditentukan oleh drainase, tekstur, struktur, dan konsistensi tanah, serta kedalaman efektif (FAO, 1983 dalam Djaenudin et al., 2003). Evaluasi kesesuaian lahan perlu dilakukan agar menjadi dasar pertimbangan dalam pengambilan keputusan penggunaan lahan yang sesuai dengan kesesuaiannya (Ritung, et al., 2011).

Evaluasi kesesuaian lahan seperti yang dianjurkan Food and Agriculture Organization (FAO) akan memberikan informasi tentang kelas kecocokan penggunaan suatu wilayah untuk komoditas tertentu (FAO, 1976 dalam Banjarnahor dan Simanjuntak, 2015). Secara spesifik, kesesuaian lahan untuk suatu komoditas dinilai berdasarkan sifat-sifat fisik lingkungan, seperti tingkat kesuburan tanah, iklim, topografi, hidrologi dan drainase (Supriyadi et al., 2009 dalam Mutiara, 2015). Kelas kesesuaian lahan terdiri dari: 1) kelas Sangat Sesuai (S1) berarti lahan tidak memiliki faktor pembatas yang nyata terhadap produksi tanaman sehingga produktivitas mampu mencapai rentang $100-80 \%$ dari potensinya, 2) kelas Cukup Sesuai (S2) berarti lahan mempunyai faktor pembatas yang akan menurunkan produktivitas tanaman sehingga hanya mencapai hasil 80-60\% dari potensinya, 3) kelas Sesuai Marjinal (S3) berarti lahan mempunyai faktor pembatas yang berat sehingga produktivitas tanaman hanya berkisar pada rentangan 60-40\% dari potensinya, dan 4) kelas Tidak Sesuai (N) berarti terdapat faktor pembatas yang sangat berat sehingga produktivitas tanaman hanya mencapai maksimal 40\% dari potensinya (Banjarnahor \& Simanjuntak, 2016). Penilaian lahan atau evaluasi lahan dimaksud untuk menilai tanaman dapat tumbuh dengan optimal dan mengetahui faktor pembatas lahan tersebut yang nantinya akan berpengaruh pada penurunan produksi, sehingga perlu dilakukan penekanan terhadap faktor pembatas, serta memperbaiki kondisi lahan supaya bisa meningkatkan produksi tanaman (Rabia, 2012).

Berdasarkan latar belakang di atas maka penelitian ini dilakukan untuk mengetahui karakteristik lahan dan kesesuaian lahan tanaman pangan di Kecamatan Ngaha Ori Anggu Kabupaten Sumba Timur. Hasil dari penelitian ini, kiranya memberikan informasi yang teoritis dan ilmiah tentang lokasi-lokasi yang sesuai untuk pengembangan tanaman pangan agar dapat meningkatkan produktivitas tanaman pangan di kabupaten ini khususnya di Kecamatan Ngaha Ori Anggu.

\section{BAHAN DAN METODE}

\section{Tempat dan waktu penelitian}

Penelitian dilaksanakan di Kecamatan Ngaha Ori Anggu Kabupaten Sumba Timur Provinsi Nusa Tenggara Timur dan sampel tanah dianalisis di Laboratorium Terpadu Universitas Kristen Wira Wacana Sumba pada bulan AprilSeptember 2020.

\section{Alat dan bahan}

Alat yang digunakan dalam penelitian ini adalah GPS, plastik, kertas label, alat tulis, dan alat-alat laboratorium untuk analisis tanah. Bahan yang digunakan adalah bahanbahan yang dipakai untuk menganalisis tekstur, drainase/redoks, pH, Kapasitas Tukar Kation (KTK) tanah.

\section{Metode analisis}

\section{Analisis Karakteristik Lahan (iklim dan tanah)}

Analisis karakteristik lahan dilakukan untuk mengenal kondisi iklim dan tanah di Kecamatan Ngaha Ori Anggu. Karakter lahan diperoleh dengan cara mengumpulkan data iklim (suhu dan curah hujan) dari 7 stasiun klimatologi yang ada di Kabupaten Sumba Timur, penggunaan lahan, kelerengan, jenis tanah serta mengambil dan menganalisis sampel tanah. Analisis sampel tanah meliputi tekstur, drainase (redoks), kedalaman tanah, batuan permukaan, bahan kasar, Kapasitas Tukar Kation (KTK), C-organik, pH. Data iklim yang digunakan adalah data curah hujan 20082018, Informasi curah hujan dan suhu udara diperoleh dari BMKG Provinsi Nusa Tenggara Timur. 
Analisis Kesesuaian Lahan

Penilaian kesesuaian lahan dilakukan dengan menggunakan 2 (dua) metode, yaitu:

1. Metode Pencocokan atau Matching yaitu membandingkan antara karakteristik lahan diperoleh di lapangan serta hasil analisis laboratorium dengan kriteria kesesuaian lahan berdasarkan persyaratan tumbuh tanaman menurut informasi dari Djaenudin et al., 2003.

2. Metode Overlay (tumpang tindih) peta karakteristik lahan dengan pemberian skor dan bobot yang berimbang pada karakteristik iklim dan tanah melalui extensions modelbuilder dalam software Arcview 3.2. Pemberian skor yang berimbang yaitu karakteristik iklim diberi skor 50 yang dibagi antara curah hujan dan suhu, sedangkan karakteristik tanah diberi skor 50 yang terbagi 5 untuk karakteristik tanah meliputi drainase (redoks), tekstur, bahan kasar, kedalaman efektif, KTK, $\mathrm{pH}$, C-Organik, batuan permukaan, dan 10 untuk kelerengan. Pembobotan dilakukan berdasarkan pada kesesuaian lahan tanaman dengan nilai bobot 4 pada kesesuaian S1, bobot 3 pada kesesuaian S2, bobot 2 pada kesesuaian S3, dan bobot 1 pada kesesuaian N. Hasil interpretasi berupa data kemudian di convert ke dalam data spasial menggunakan software ArcView 3.2 dengan proses digitasi peta untuk menyajikan peta-peta digital dan produknya. Peta yang dihasilkan adalah peta kesesuaian lahan untuk tanaman pangan di Kecamatan Ngaha Ori Anggu.

\section{HASIL DAN PEMBAHASAN}

\section{Karakteristik lahan}

Kecamatan Ngaha Ori Anggu memiliki karakteristik lahan yang begitu beragam mulai dari iklim, tanah hingga topografi. Curah hujan berdasarkan analisis data dari 7 stasiun klimatologi diperoleh rata-rata 760-1.600 mm/tahun. Suhu udara di kecamatan berkisar antara $21,7{ }^{\circ} \mathrm{C}$ hingga $27,7{ }^{\circ} \mathrm{C}$ menurut perhitungan dengan persamaan Braak (1928 lihat Djaenudin et al. 2003).

Kondisi tanah wilayah sangat beragam, dimana terdapat tiga jenis tanah yaitu andisols, inceptisol, dan mollisol dengan sifat tanahnya beragam yaitu tekstur tanah terdiri dari liat, lempung berliat dengan dengan nilai $\mathrm{pH}$ 4-8. Drainasi yang diketahui berdasarkan pengukuran potensial redoks dalam kondisi reduksi atau selalu tergenang (sangat terhambat) saat tanah mengalami jenuh air. Kandungan COrganik dan nilai kapasitas tukar kation (KTK) dalam tanah bervariasi dari rendah sampai sangat tinggi. Bahan kasar dan batuan permukaan di daerah pengamatan tergolong sangat sedikit hingga banyak. Kedalaman efektif tanah di daerah pengamatan bervariasi dari kelas dangkal hingga dalam. Kelerengan di daerah ini bervariasi dari datar hingga curam. Hasil pengukuran pada karakteristik wilayah, panduan klasifikasi berdasarkan modifikasi (Djaenudin et al., 2003) terlampir pada tabel 1.

\section{Evaluasi kesesuaian lahan}

Evaluasi lahan merupakan suatu proses penilaian sumberdaya lahan untuk tujuan tertentu dengan menggunakan suatu pendekatan atau cara yang sudah teruji. Hasil evaluasi lahan akan memberikan informasi dan arahan penggunaan lahan sesuai keperluan. Kesesuaian lahan adalah tingkat kecocokan sebidang lahan untuk penggunaan tertentu (Tumpubolon et al., 2015).

Fudhall et al. (2016) menyatakan, evaluasi kesesuaian lahan merupakan salah satu komponen penting dalam proses perencanaan penggunaan lahan yang dipergunakan untuk perencanaan penggunaan lahan yang optimum dalam bentuk tata guna lahan. Lebih lanjut dijelaskan oleh (Arsyad, 2007) bahwa, evaluasi lahan merupakan penghubung antara berbagai aspek dan kualitas fisik, biologi dan teknologi penggunaan lahan dengan tujuan sosial ekonomi. Kesesuaian lahan diperlukan untuk budidaya tanaman agar mendapat pertumbuhan yang optimal, walaupun tanaman bisa tumbuh pada suatu lahan, akan tetapi belum tentu lahan tersebut sesuai untuk tanaman tertentu (Mutiara, 2015). Kegiatan budidaya tanaman pada suatu lahan perlu dilakukan evaluasi lahan agar produksi yang dihasilkan sesuai dengan produksi optimal dari tanaman tersebut.

\section{a. Kesesuaian Lahan Tanaman Padi Tadah Hujan}

Hasil analisis kesesuaian lahan metode overlay (tumpang tindih) peta diperoleh kelas kesesuaian lahan tanaman padi tadah hujan di Kecamatan Ngaha Ori Anggu (gambar 1) yaitu: Kelas kesesuaian S1 (Sangat Sesuai) 10.575 ha $(24,47 \%)$, S2 (Cukup Sesuai) 32.614 ha (75,53\%). Dari hasil analisis terlihat bahwa Kecamatan Ngaha Ori Anggu sebagian besar wilayahnya masih didominasi dengan kelas kesesuaian lahan S2 (Cukup Sesuai) untuk budidaya dan pengembangan tanaman padi tadah hujan. Akan tetapi untuk wilayah yang kesesuaian lahan S2 (Cukup Sesuai) dapat ditingkatkan kelas kesesuaiannya dengan cara perbaikan terhadap faktor-faktor pembatas yang ada kesesuaiannya menjadi S1 (Sangat Sesuai). Faktor pembatas utama dari hasil pencocokan atau matching parameter karakteristik lahan dengan kriteria kesesuaian lahan menurut Djaenudin et al. (2003) adalah ketersediaan oksigen (ao) seperti drainase, bahaya erosi (eh) atau lereng.

Perbaikan faktor pembatas dilakukan agar terjadi peningkatan kelas kesesuaian lahannya. Faktor pembatas drainase dapat menentukan jenis tanaman yang dapat tumbuh karena berhubungan dengan ketersediaan oksigen dalam tanah. Pada daerah dengan drainase sangat terhambat tidak berpengaruh karena tanaman padi mempunyai sistem pertukaran $\mathrm{O}_{2}$ internal akar-tajuk sehingga walaupun tergenang, mereka masih bisa berespirasi (Utomo et al., 2016) 
Tabel 1. Rata-rata karakteristik lahan di Kecamatan Ngaha Ori Anggu

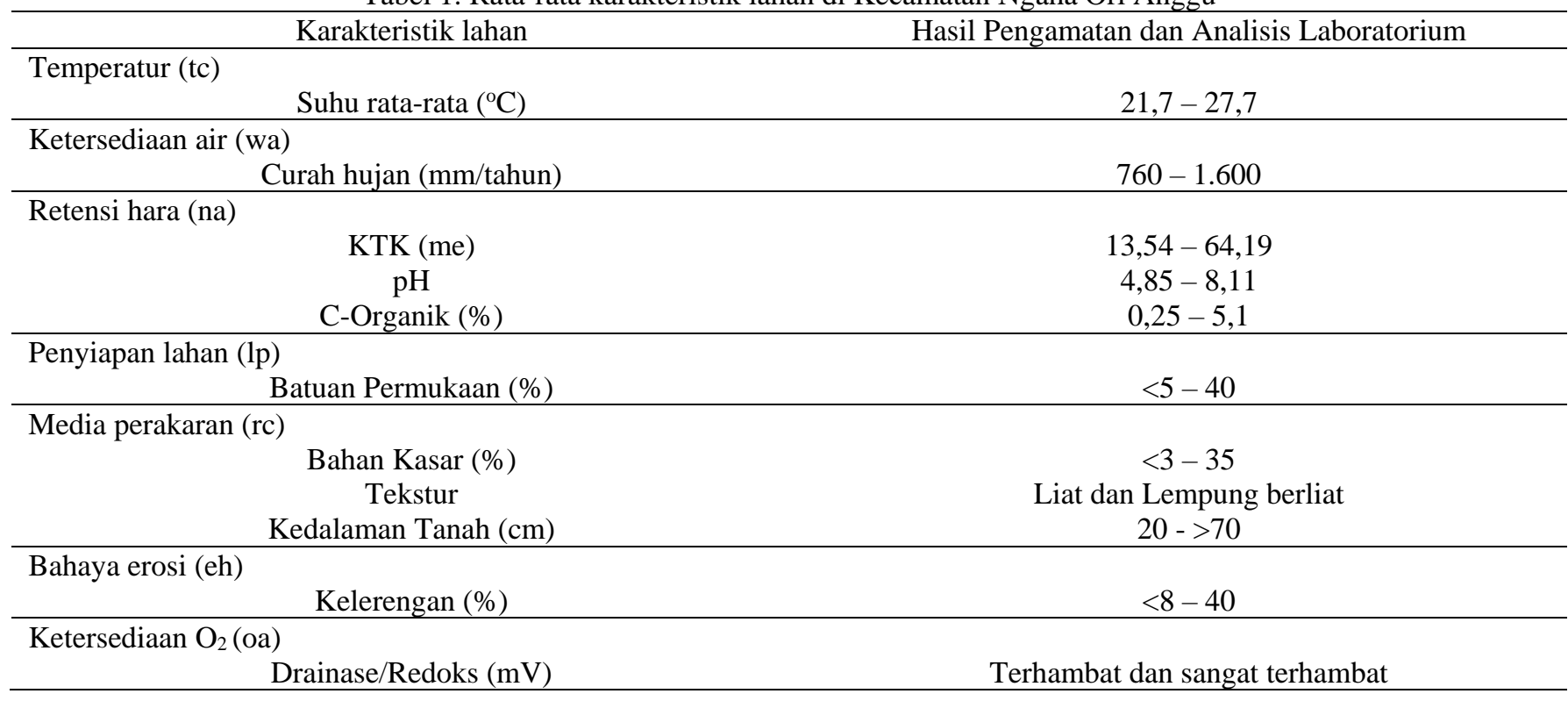
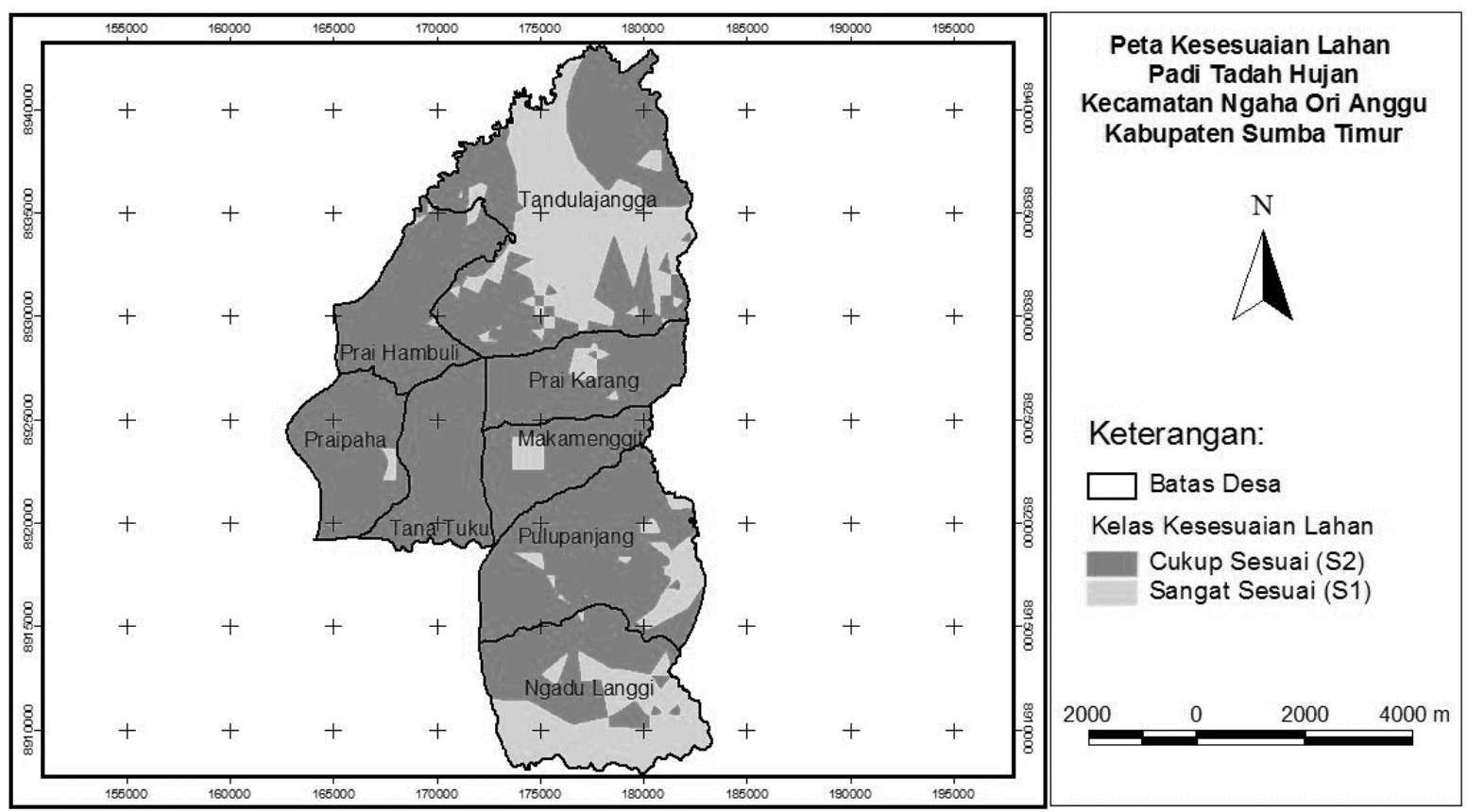

Gambar 1. Peta kelas kesesuaian lahan tanaman padi tadah hujan Kecamatan Ngaha Ori Anggu.

Perbaikan terhadap faktor pembatas drainase dilakukan dengan membuat jalur pembuangan air atau selokan yang memudahkan air dapat berpindah dari lokasi budidaya. Faktor pembatas kelerengan berkaitan dengan terjadinya erosi permukaan yang dapat mengurangi tingkat kesuburan lahan. Faktor kelerengan dapat diperbaharui dengan beberapa cara, salah satunya dengan membuat teras di daerah miring agar mengurangi terjadinya erosi (Juarsah et al., 2008).

\section{b. Kesesuaian Lahan Tanaman Jagung}

Berdasarkan hasil analisis kesesuaian lahan metode overlay (tumpang tindih) peta diperoleh kelas kesesuaian lahan tanaman jagung di Kecamatan Ngaha Ori Anggu (gambar 2) yaitu: Kelas Kesesuaian S1 (Sangat Sesuai) 890,7 ha $(2,06 \%)$ dan S2 (Cukup Sesuai) 42.327 ha $(97,92 \%)$. Kelas kesesuaian lahan S2 merupakan kelas kesesuaian yang sangat dominan karena mencakup hampir seluruh wilayah Kecamatan Ngaha Ori Anggu. Akan tetapi, untuk meningkatkan kelas kesesuaian lahan untuk tanaman jagung ke kelas kesesuaian S1 diperlukan pengelolaan terhadap faktor-faktor pembatas yang ada. 


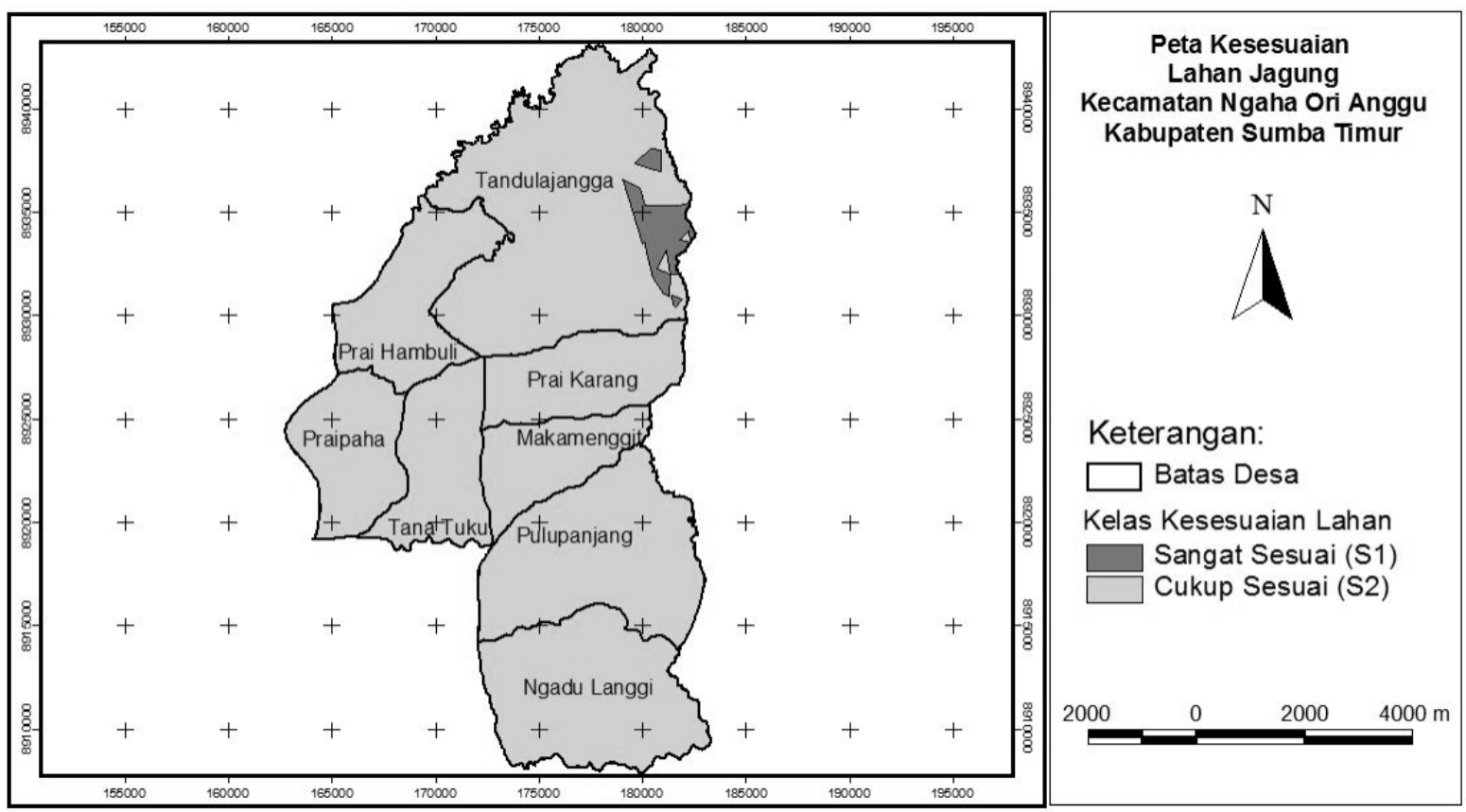

Gambar 2. Peta kelas kesesuaian lahan tanaman jagung Kecamatan Ngaha Ori Anggu

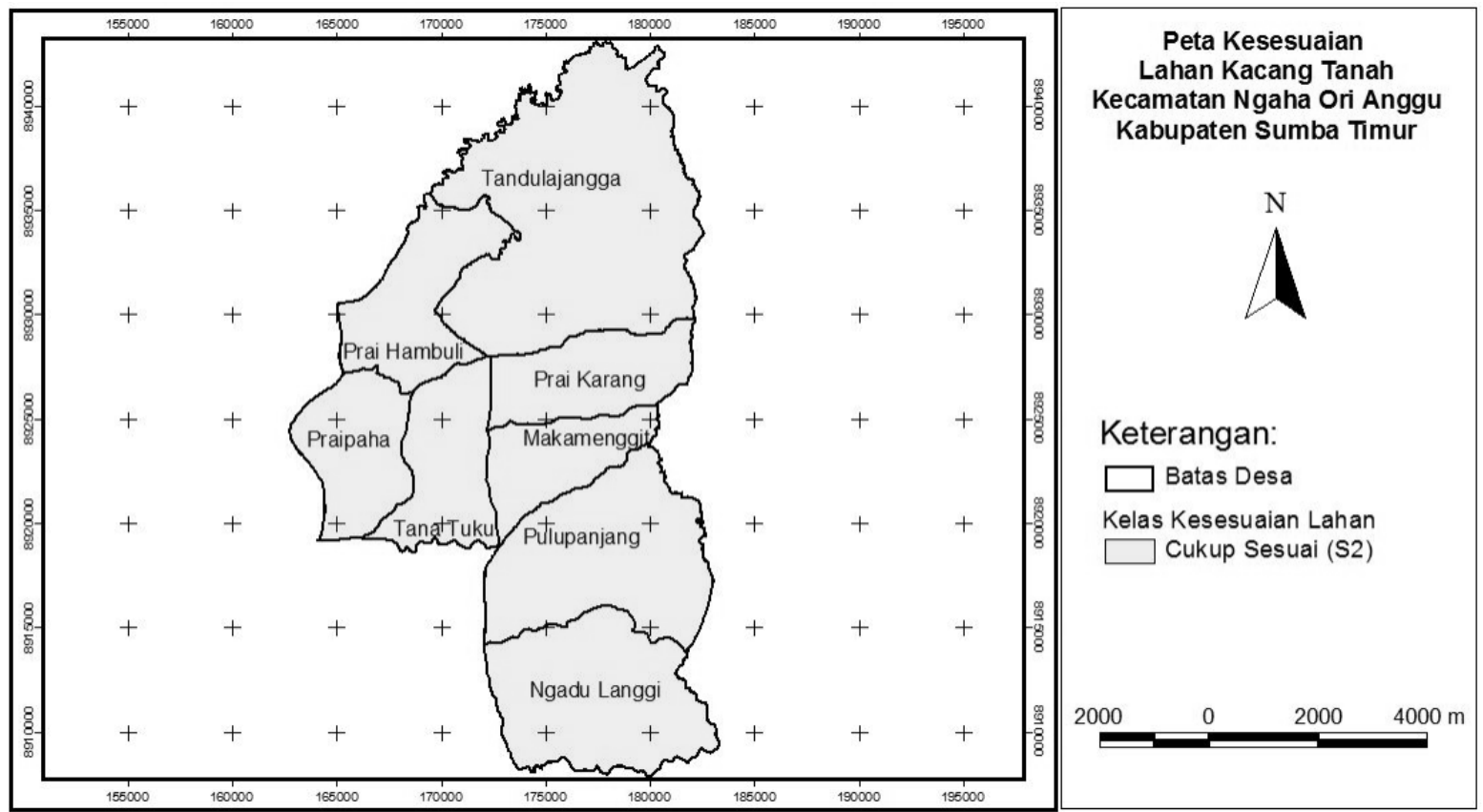

Gambar 3. Peta kelas kesesuaian lahan tanaman kacang tanah Kecamatan Ngaha Ori Anggu

Faktor pembatas utama berdasarkan hasil pencocokan atau matching diperoleh faktor pembatas ketersediaan oksigen (ao) seperti drainase, dan bahaya erosi (eh) atau lereng. Faktor pembatas ketersediaan oksigen dapat untuk drainase pada tanaman jagung dapat diperbaharui atau ditingkatkan kelas kesesuaiannya dengan usaha perbaikan irigasi dan pembuatan saluran drainase (Wirosoedarmo et al., 2011). Drainase yang baik diperlukan oleh tanaman yang membutuhkan aerasi yang baik seperti jagung. Aerasi tanah yang baik menyebabkan di dalam tanah cukup tersedia oksigen. Dengan demikian, akar tanaman mampu menyerap unsur hara dan dapat berkembang dengan baik (Wirosoedarmo et al., 2011). Faktor pembatas kelerengan berkaitan dengan terjadinya erosi permukaan yang salah satunya dapat mengurangi tingkat kesuburan lahan. Faktor pembatas bahaya erosi tanaman jagung dapat dikelola dengan pemotongan lereng dengan sistem teras gulud dan teras bangku untuk mengurangi erosi tanah (Wirosoedarmo et al., 2011). 


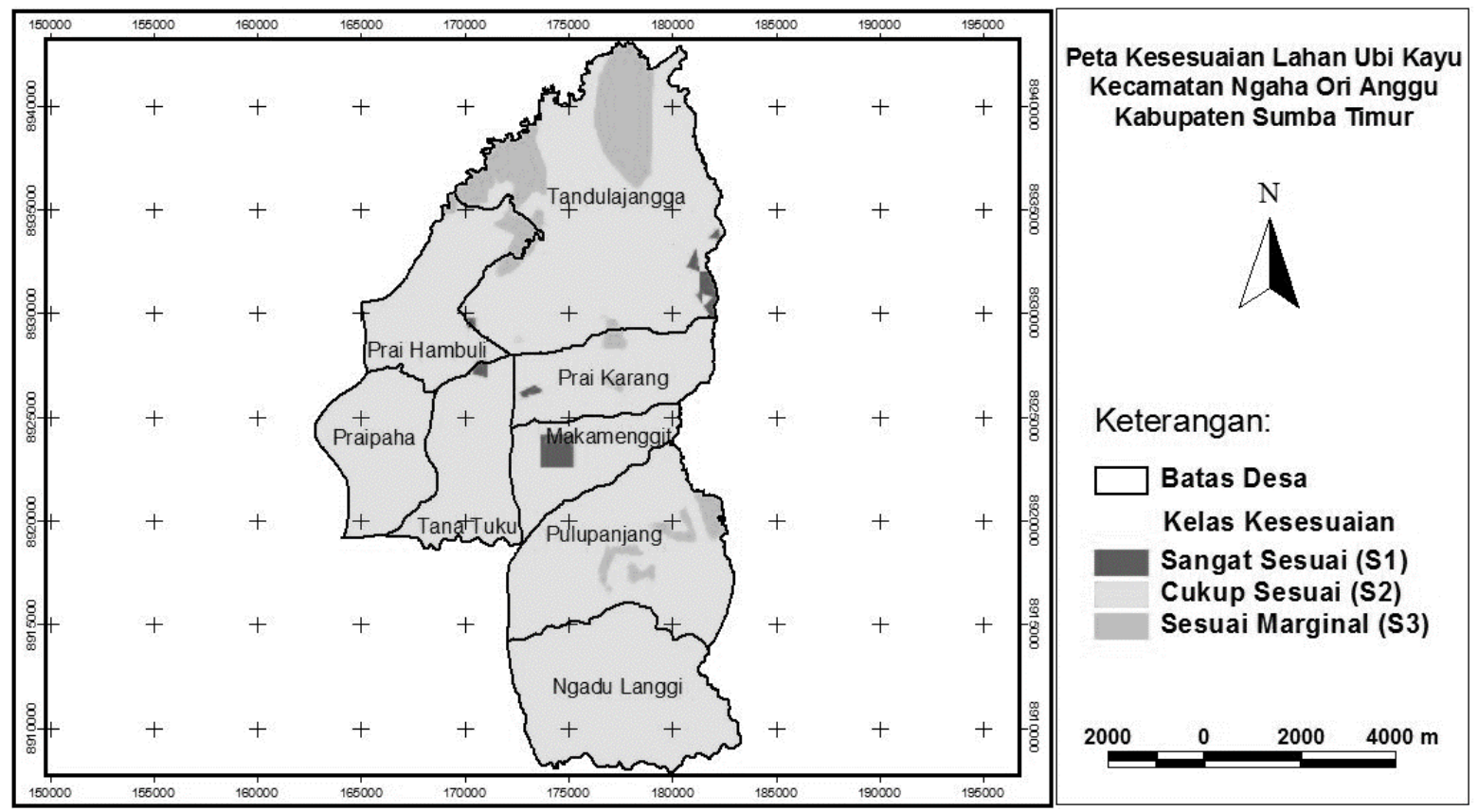

Gambar 4. Peta kelas kesesuaian lahan tanaman ubi kayu Kecamatan Ngaha Ori Anggu.

\section{c. Kesesuaian Lahan Tanaman Kacang Tanah}

Berdasarkan hasil analisis kesesuaian lahan metode overlay (tumpang tindih) peta diperoleh kelas kesesuaian lahan tanaman kacang tanah di Kecamatan Ngaha Ori Anggu (gambar 3) yaitu: didominasi kelas kesesuaian S2 (Cukup Sesuai) 43.216 ha $(100 \%)$. Kelas kesesuaian kacang tanah di kecamatan Ngaha Ori Anggu dapat ditingkatkan kelas kesesuaian lahannya ke kelas kesesuaian S1 diperlukan pengelolaan terhadap faktor-faktor pembatas yang ada.

Faktor pembatas utama berdasarkan hasil pencocokan (matching) diperoleh faktor pembatas ketersediaan oksigen (ao) seperti drainase, ketersediaan air (wa) atau curah hujan, bahaya erosi (eh) atau lereng. Perbaikan terhadap drainase perlu dilakukan dengan pembuatan saluran-saluran drainase yang berfungsi untuk menyalurkan air keluar dari lokasi pertanaman (Winarno, et al., 2010). Faktor pembatas ketersediaan air mempengaruhi pertumbuhan tanaman kacang tanah. Kacang tanah dapat tumbuh dengan baik jika air yang tersedia cukup untuk kebutuhannya, akan tetapi jika berlebihan akan mempengaruhi pertumbuhan akarnya. Faktor pembatas bahaya erosi atau lereng dapat dilakukan upaya perbaikan dengan pembuatan teras yang berfungsi memotong panjang lereng sehingga mengurangi besarnya erosi (Winarno, et al., 2010).

\section{d. Kesesuaian Lahan Tanaman Ubi Kayu}

Berdasarkan hasil analisis kesesuaian lahan metode overlay (tumpang tindih) peta diperoleh tiga kelas kesesuaian lahan tanaman ubi kayu di Kecamatan Ngaha Ori Anggu (gambar 4.) yaitu: Kelas Kesesuaian S1 (Sangat Sesuai) 539,48 ha (1,24 \%), S2 (Cukup Sesuai) 39.214,70 ha $(90,74 \%)$, dan S3 (Sesuai Marginal) 3.462, 80 ha $(8,01 \%)$.
Kelas kesesuaian lahan S2 merupakan kelas kesesuaian yang dominan yang mencakup hampir seluruh wilayah Kecamatan Ngaha Ori Anggu. Akan tetapi, untuk meningkatkan kelas kesesuaian lahan untuk tanaman jagung ke kelas kesesuaian S1 diperlukan pengelolaan terhadap faktor-faktor pembatas yang ada.

Faktor pembatas utama dari hasil pencocokan atau matching diperoleh faktor pembatas ketersediaan oksigen (ao) seperti drainase, temperatur (tc) atau temperatur rerata $\left({ }^{\circ} \mathrm{C}\right)$, bahaya erosi (eh) atau lereng. Faktor pembatas ketersediaan oksigen dapat untuk drainase pada lahan dapat diperbaharui dengan membuat selokan atau saluran air dan menambah bahan organik agar tanah dapat mempertahankan kualitasnya sebagai hasil kerja dari mikroorganisme tanah (Nganji, et al., 2018). Faktor pembatas kelerengan berkaitan dengan terjadinya erosi permukaan yang salah satunya dapat mengurangi tingkat kesuburan lahan. Faktor pembatas bahaya erosi dan upaya perbaikan yang dilakukan adalah dengan pembuatan teras-teras (Winarno, et al., 2010).

\section{KESIMPULAN}

Kecamatan Ngaha Ori Anggu memiliki karakteristik lahan yang bervariasi, baik karakteristik iklim maupun karakteristik tanahnya. Berdasarkan analisis data iklim diperoleh kondisi curah hujan berkisar antara $760-1.600$ $\mathrm{mm} /$ tahun, dengan suhu rata-rata antara $21,1-27,7{ }^{\circ} \mathrm{C}$. Kondisi karakteristik tanah diantaranya drainase sangat terhambat (nilai redoksnya $-42-144 \mathrm{mV}$ ), tekstur halus (liat), agak halus (lempung berliat). Karakteristik bahan kasar mulai dari sangat sedikit sampai sedang $(<3->35 \%)$, kedalaman tanah yaitu antara $20 \mathrm{~cm}$ hingga $>75 \mathrm{~cm}$ (sangat dangkal hingga dalam), nilai kapasitas tukar kation yaitu 25 - 64,19 cmol (harkat rendah sampai harkat tinggi), kondisi reaksi tanah $(\mathrm{pH})$ agak masam sampai alkalis $(4,85-8,11)$, C-organik 
tanah berkisar antara 0,25 - 5,1\% (rendah hingga tinggi). Wilayah Kecamatan Ngaha Ori Anggu berlereng <8 - >40\% (datar sampai curam), batuan permukaan tidak ada atau sangat sedikit hingga sangat banyak $(<5-40 \%)$.

Sesuai dengan analisis kelas kesesuaian lahan dengan metode overlay parameter pengamatan dengan menggunakan sistem informasi geografis (GIS) melalui extension model builder diperoleh kelas kesesuaian lahan tanaman padi tadah hujan di Kecamatan Ngaha Ori Anggu yaitu: : Kelas kesesuaian S1 (Sangat Sesuai) 10.575 ha (24,47 \%), S2 (Cukup Sesuai) 32.614 ha (75,53\%). Kelas kesesuaian lahan tanaman jagung yaitu: Kelas Kesesuaian S1 (Sangat Sesuai) 890,7 ha $(2,06 \%$ ) dan S2 (Cukup Sesuai) 42.327 ha $(97,92$ $\%)$. Kelas kesesuaian lahan tanaman kacang tanah yaitu: Kelas kesesuaian S2 (Cukup Sesuai) 43.216 ha (100\%). Kelas kesesuaian lahan tanaman ubi kayu yaitu: Kelas Kesesuaian S1 (Sangat Sesuai) 539,48 ha (1,24 \%), S2 (Cukup Sesuai) 39.214,70 ha $(90,74 \%$ ), dan S3 (Sesuai Marginal) $3.462,80$ ha $(8,01 \%)$. Hasil pencocokan atau matching parameter karakteristik lahan dengan kriteria kesesuaian lahan tanaman menurut Djaenudin et al. (2003) diperoleh faktor pembatas utama yaitu ketersediaan oksigen (ao) seperti drainase, bahaya erosi (eh) atau lereng, ketersediaan air (wa) atau curah hujan, temperatur (tc) atau temperatur rerata $\left({ }^{\circ} \mathrm{C}\right)$.

\section{UCAPAN TERIMA KASIH}

Penulis mengucapkan limpah terima kasih kepada Universitas Kristen Wira Wacana Sumba yang telah membiayai penelitian ini melalui skema Penelitian Dosen Mandiri (PDM) tahun 2020.

\section{DAFTAR PUSTAKA}

Arsyad, S. (2007). Konservasi Tanah dan Air. Bogor: IPB Press.

Azis, A., Sunarminto, B. H., \& Renanti, M. D. (2006). Evaluasi Kesesuaian Lahan untuk Budidaya Tanaman Pangan Menggunakan Jaringan Syaraf Tiruan. Berkala MIPA, 16(1), 1-10.

Balai Penelitian Tanah. (2003). Petunjuk Teknis Evaluasi Lahan untuk Komoditas Pertanian. Bogor: P3TA. Badan Litbang Pertanian.

Banjarnahor, D., \& Simanjuntak, B. H. (2016). Evaluasi Kesesuaian Lahan Sumba Tengah Untuk Tanaman Pangan Serta Perancangan Pola Tanamnya Yang Spesifik Lokasi. Bumi Lestari, 16(2), 108-118.

Djaenudin, D., H, M., H, S., \& Hidayat, A. (2003). Petunjuk Teknis Evaluasi Lahan untuk Komoditas Pertanian. Bogor: Balai Penelitian Tanah, Puslitbangtanak.
Fudhall, M., Paloloang, A. K., \& Rahman, A. (2016). Evaluasi Kesesuaian Lahan untuk Pengembangan Tanaman Cengkeh (Eugenia aromatica L) Di Desa Marowo dan Bonevoto Kecamatan Ulubongka Kabupaten Tojo Una-Una. E-J. Agrotekbis, 4(2), 142150 .

Hardjowigeno, S., \& Widiatmaka. (2007). Evaluasi Kesesuain Lahan dan Perencanaan Tataguna Lahan. Yogyakarta: Universitas Gadja Mada Press.

Juarsah, I., Yustika, R. D., \& Abdurachman, A. (2008). Pengendalian erosi dan kahat bahan organik tanah pada lahan kering berlereng mendukung produksi pangan nasional. In Seminar Nasional dan Dialog Sumberdaya Lahan Pertanian (pp. 18-20). Bogor: Balai Besar Penelitian dan Pengembangan Sumberdaya Lahan Pertanian.

Mutiara, E. (2015). Kesesuaian Lahan Untuk Tanaman Kacang Tanah di Desa Sampuran, Kecamatan Ranto Baek, Kabupaten Mandailing Natal. Nasional Ecopedon, 2(2), 1-4.

Nganji, M. U., Simanjuntak, B. H., \& Suprihati. (2018). Evaluasi Kesesuaian Lahan Komoditas Pangan Utama di Kecamatan Umbu Ratu Nggay Barat Kabupaten Sumba Tengah. Agritech, 38(2), 172-177.

Rabia, A. H. (2012). A GIS based land suitability assessment for agricultural planning in Kilte Awulaelo district, Ethiopia. In The 4th International Congress of ECSS (pp. 1-10). Bari, Italy: EUROSOIL.

Ritung, S., Nugroho, K., Mulyani, A., \& Suryani, E. (2011). Petunjuk Teknis Evaluasi Lahan untuk Komoditas Pertanian (Edisi revisi). Bogor: Balai Besar Penelitian dan Pengembangan Sumberdaya Lahan Pertanian, Badan Penelitian dan Pengembangan Pertanian.

Tumpubolon, K., Razali, \& Guchy, H. (2015). Evaluasi Kesesuaian Lahan Tanaman Padi Sawah Irigasi (Oryza sativa L.) di Desa Bakaran Batu Kecamatan Sei Baban Kabupaten Serdang Bedagi. Jurnal Online Agroekoteknologi, 3(2), 732-739.

Utomo, M., Sabrina, T., Sudarsono, Lumbanraja, J., Rusman, B., \& Wawan. (2016). Ilmu Tanah: Dasar-dasar dan Pengelolaan. Jakarta: Prenadamedia Group.

Winarno, J., Rachmadhika, Y., \& Supriyadi. (2010). Evaluasi kesesuaian "beberapa jenis tanaman" dalam sistem wanatani di wilayah desa ngadipiro kecamatan nguntoronadi kabupaten wonogiri. Sain Tanah-Jurnal Ilmu Tanah Dan Agroklimatologi, 7(2), 97-110.

Wirosoedarmo, R., Sutanhaji, A. T., Kurniati, E., \& Wijayanti, R. (2011). Evaluasi kesesuaian lahan untuk tanaman jagung menggunakan metode analisis spasial. Agritech, 31(1), 71-78. https://doi.org/https://doi.org/10.22146/agritech.9728 